\title{
R\&D Activities in Oligopoly and Social Welfare
}

\begin{abstract}
This paper analyzes the impact of R\&D activities in an oligopoly on consumer surplus and social welfare. We use a two-stage model to analyze the behavior of duopolists at the research level, and in the final-product market, under the assumption of linear and quadratic cost functions. Three options for firm competition are considered: 1) Cournot competition at both stages; 2) cooperation at the R\&D stage and Cournot competition in the final-product market; and 3) cooperation at both stages. Numerical simulations for various levels of $\mathrm{R} \& \mathrm{D}$ spillovers are conducted to analyze the welfare effects of firm decisions. We conclude that for high levels of technological spillovers, total welfare is highest when firms engage in cooperation at the R\&D stage, and compete in the final product market, independent of the shape of cost functions. However, the functional form of production costs has a qualitative impact on welfare when firms fully compete.
\end{abstract}

Keywords: R\&D cooperation of firms, industry cartelization, social welfare, Cournot oligopoly

JEL: L13, L41, O31

\section{Introduction}

Development of new technologies by a firm in does not take place in isolation. It is usually directly or indirectly linked to the R\&D activities conducted by other firms. Technological improvements made by one firm often generate positive externalities for 
competitors. ${ }^{3}$ The extent of cost-reducing technological spillovers may vary due to the nature of knowledge, and/or strategic decisions of firms. ${ }^{4}$ On the one hand, some information about technological improvements is naturally spread out through the industry. On the other hand, firms may contribute to raising the extent of technological spillovers by establishing some channels of R\&D cooperation.

In the oligopolistic market structure, competing firms can coordinate their $\mathrm{R} \& \mathrm{D}$ and final product market activities. The degree of cooperation affects the size of cost-reducing investments and distribution of resulting gains.

Under the assumption of linear cost function of manufacturing, d'Apremont and Jacquemin [1988] analyzed the decisions of duopolists regarding R\&D investments and the supply of the final product. They showed that the R\&D coordination, together with Cournot-type competition in the final product market, generates a higher total welfare than either no cooperation or full coordination of R\&D and the supply of the final product. This model was further extended by Kamien et al. [1992] into Bertrand competition in the product market. Their main policy conclusion was that collusion in the product market should be banned.

However, De Fraja and Silipo [2002] showed that when R\&D activity is involved, monopoly can be better than a Cournot-type competition of duopolists in the product market. Their primary conclusion was that the welfare effects of firm behavior at the R\&D stage and in the final product market strongly depend on parameter combinations. Therefore, it is problematic to formulate general rules about the welfare consequences of R\&D investments.

This paper examines the impact of R\&D activities in oligopoly on consumer surplus and total welfare under two different manufacturing cost functions. First, we investigate the social welfare and distribution of gains generated by R\&D activities in the linear cost model (similar to the one offered by d'Apremont and Jacquemin [1988]). We then conduct an analogous investigation using a quadratic cost functions of manufacturing model introduced by Prokop [2014]. Finally, we compare the results of both models and formulate conclusions regarding the welfare effects of various forms of oligopolistic competition at the R\&D stage and final-product market.

We apply numerical simulations for various levels of R\&D spillovers to analyze the decisions of firms and their impact on consumer surplus, and the resulting total welfare.

\section{Social Welfare Effects of R\&D Under Linear Cost Functions}

Following d'Apremont and Jacquemin's [1988] basic framework we first analyze duopolistic competition when the final product is manufactured according to a linear cost function, modeled as a two-player game that consists of two stages. In the first stage, both players decide on the size of R\&D expenditures, denoted $x_{i}$ for firm $i(i=1,2)$ and, 
in the second stage, choose the quantities of the final product, represented by $q_{i}$ for firm $i$. The resulting pair of vectors $\left(x_{i}, q_{i}\right)$, is a profile of strategies that constitute a symmetric pure-strategy Nash equilibrium of this game.

We assume a homogeneity of goods produced by both firms. The inverse demand function for the goods is obtained by the following formula

$$
D^{-1}(Q)=a-b Q,
$$

where $a, b$ are positive parameters and $Q\left(=q_{1}+q_{2}\right)$ is the total production of both firms.

The manufacturing costs of firm $i$ is given by the following linear function

$$
C_{i}\left(q_{i}, x_{i}, x_{j}\right)=\frac{q_{i}}{c+x_{i}+\beta x_{j}},
$$

where $c$ and $\beta$ are fixed parameters. The cost function reflects a key assumption about the effects of research efforts; that the R\&D activities of each firm generate positive externalities due to spillover effects. The strength of these spillovers is represented by exogenous parameter $\beta$, which belongs to the interval $[0 ; 1]$. Parameter $c$ describes the initial cost efficiency of each firm.

This formula for manufacturing costs differs slightly from the one used by d'Apremont and Jacquemin [1988]. In our model, effective R\&D investment is placed in the denominator of the cost function, rather than deducted from the marginal cost of production. This technical change is introduced to avoid the situation when for high values of parameter $\beta$ the marginal costs of production are negative due to over investment in research.

Each firm is assumed to incur R\&D investment costs described by the following function:

$$
\gamma \frac{x_{i}^{2}}{2}
$$

where $\gamma(\gamma>0)$ is a fixed parameter.

Now, the profit of each firm could be presented in the following form:

$$
\pi_{i}\left(q_{i}, q_{j}, x_{i}, x_{j}\right)=(a-b Q) q_{i}-\frac{q_{i}}{c+x_{i}+\beta x_{j}}-\gamma \frac{x_{i}^{2}}{2} .
$$

We consider three options for the firms' competition in our two-stage game:

1) full competition, i.e., Cournot-type competition at both stages;

2) cooperation in $R \& D$ - cooperation at the $R \& D$ stage ( $R \& D$ cartel), and Cournot competition in the final-product market;

3) full cooperation - cooperation at both stages, i.e. full cartelization of the industry. 
In each model variant, we obtain different Nash equilibria that naturally depend on the parameters of the model. The key parameter that affects the equilibria, and therefore social welfare, is the level of spillovers, $\beta$. The result of the game is a symmetric Nash equilibrium in pure strategies, in the form of an optimal pair of values of strategic variables $\left(x_{i}^{*}, q_{i}^{*}\right)$, for $i=1,2$.

We conduct a numerical analysis to obtain the equilibrium values of strategic variables, as well as the size and distribution of gains from R\&D investments. In our simulations, the following levels of the parameters have been assumed: $a=100, c=1, b=1, \gamma=2$, and $\beta \in[0,1]$.

First, we consider the case of full competition between enterprises, i.e., the firms simultaneously and independently choose the size of R\&D investments at the initial stage, and the quantities of supply at the second stage. Table 1 shows the equilibrium results in this case. In addition to the equilibrium values of production $q_{i}$, market price $p$, the level of R\&D investments $x_{i}$, the table contains the size of total welfare, $T W$, and its distribution into consumer surplus, $C S$, and profits $\pi_{i}$. Consumer surplus is calculated as the area under the demand curve and above the level of the market price of the total quantity of production. Total welfare is obtained as the sum of the consumer surplus and the profits of both firms.

TABLE 1. Cournot equilibrium for linear cost functions and various levels of spillovers

\begin{tabular}{|c|c|c|c|c|c|c|}
\hline$\beta$ & $q_{i}$ & $p$ & $x_{i}$ & $C S$ & $\pi_{i}$ & $T W$ \\
\hline 0,0 & 33,2287 & 33,5426 & 2,18447 & 2208,293 & 1099,37 & 4407,033 \\
\hline 0,1 & 33,2300 & 33,5400 & 2,02305 & 2208,466 & 1100,14 & 4408,746 \\
\hline 0,2 & 33,2310 & 33,5380 & 1,88030 & 2208,599 & 1100,76 & 4410,119 \\
\hline 0,3 & 33,2316 & 33,5368 & 1,75239 & 2208,678 & 1101,27 & 4411,218 \\
\hline 0,4 & 33,2320 & 33,5360 & 1,63643 & 2208,732 & 1101,69 & 4412,112 \\
\hline 0,5 & 33,2322 & 33,5356 & 1,53019 & 2208,758 & 1102,04 & 4412,838 \\
\hline 0,6 & 33,2320 & 33,5360 & 1,43188 & 2208,732 & 1102,32 & 4413,372 \\
\hline 0,7 & 33,2316 & 33,5368 & 1,34007 & 2208,678 & 1102,55 & 4413,778 \\
\hline 0,8 & 33,2310 & 33,5380 & 1,25354 & 2208,599 & 1102,73 & 4414,059 \\
\hline 0,9 & 33,2300 & 33,5400 & 1,17124 & 2208,466 & 1102,86 & 4414,186 \\
\hline 1,0 & 33,2287 & 33,5426 & 1,09224 & 2208,293 & 1102,95 & 4414,193 \\
\hline
\end{tabular}

S o u r c e: own calculations.

From Table 1, it follows that the R\&D investments of each firm decline in response to an increase in the level of research spillovers. A larger size of externalities could reduce the extent of replication in research activities to achieve the same level of cost reduction. The equilibrium supply of the final product achieves the highest value for the level of 
spillovers equal 0,5. The market price is the lowest in this case. Therefore, it is the best size of spillovers from the viewpoint of consumers, i.e. the consumer surplus achieves the highest value. However, the profits of firms are positively correlated with the extent of spillover effects. Total welfare is maximized for spillover levels close to 1,0 (to be precise, the maximum of $T W$ is reached for $\beta=0,99)$. this positive social welfare response to increases in the value of parameter $\beta$ results from the relatively small decrease of consumer surplus, along with a relatively high reduction of production costs, generated by the higher scope of positive externalities.

Next, we consider the cooperation of firms at the R\&D stage and Cournot competition in the final-product market. Enabling R\&D coordination allows firms to better utilize their resources. The equilibrium values of strategic variables and size of social welfare are presented in Table 2.

Cooperative behavior of firms at the $R \& D$ stage does not change the negative sign of the relationship between spillover levels and the amount of research investments- the investments are declining with an increasing values of parameter $\beta$. However, each firm's production level increases with greater technological spillovers, despite declining R\&D investments. The greater supply of the final product due to larger spillovers leads to a lower market price, which contributes to an increase in consumer surplus. The highest consumer benefits are realized when there is perfect exchange of knowledge between firms, i.e., $\beta=1$.

TABLE 2. Equilibrium in the model of R\&D cooperation under linear cost functions

\begin{tabular}{|c|c|c|c|c|c|c|}
\hline$\beta$ & $q_{i}$ & $p$ & $x_{i}$ & $C S$ & $\pi_{i}$ & $T W$ \\
\hline 0,0 & 33,2059 & 33,5882 & 1,61663 & 2205,264 & 1100,02 & 4405,304 \\
\hline 0,1 & 33,2125 & 33,5750 & 1,59941 & 2206,140 & 1100,51 & 4407,160 \\
\hline 0,2 & 33,2183 & 33,5634 & 1,58187 & 2206,911 & 1100,95 & 4408,811 \\
\hline 0,3 & 33,2235 & 33,5530 & 1,56435 & 2207,602 & 1101,35 & 4410,302 \\
\hline 0,4 & 33,2280 & 33,5440 & 1,54708 & 2208,200 & 1101,71 & 4411,620 \\
\hline 0,5 & 33,2322 & 33,5356 & 1,53019 & 2208,758 & 1102,04 & 4412,838 \\
\hline 0,6 & 33,2359 & 33,5282 & 1,51374 & 2209,250 & 1102,34 & 4413,930 \\
\hline 0,7 & 33,2393 & 33,5214 & 1,49778 & 2209,702 & 1102,61 & 4414,922 \\
\hline 0,8 & 33,2425 & 33,5150 & 1,48232 & 2210,128 & 1102,86 & 4415,848 \\
\hline 0,9 & 33,2453 & 33,5094 & 1,46737 & 2210,500 & 1103,10 & 4416,700 \\
\hline 1,0 & 33,2480 & 33,5040 & 1,45292 & 2210,859 & 1103,32 & 4417,499 \\
\hline
\end{tabular}

S ource: own calculations.

By allowing firms to cooperate in their research activities, we observe relatively smaller R\&D investments in comparison to the competitive outcome for low spillover levels $(\beta<0,5)$, and relatively greater research involvement than in a non-cooperative environment for 
the large extent of development externalities $(\beta>0,5)$. An analogous relationship is true for production equilibrium levels, since they are positively correlated with R\&D activities.

Since consumer surplus is closely linked to production levels, it responds to changes in the size of R\&D spillovers in the same fashion as firm output, i.e. CS is relatively smaller in comparison to the non-cooperative outcome for lower spillover values, and relatively bigger for large levels of research externalities. Firm profits are naturally higher when cooperation is allowed; otherwise the idea of cooperation would be abandoned. However, the increase in firm profits is relatively low in comparison to the difference that cooperation makes for customers. Therefore, total welfare responds to coordinating research investments in the same way as consumer surplus. Thus, the cooperative behavior of firms at the R\&D stage positively impacts social welfare, provided that the technological spillovers are large.

Finally, we consider the case of full cooperation by firms at both stages of the game. Table 3 presents the equilibrium values of the fully coordinated decisions of players. Therefore, one can infer that the situation has changed in terms of market concentration from a duopoly to a monopoly or cartel that controls two R\&D units linked by spillovers and subject to diseconomies of scale.

It follows from Table 3 that cooperation at both stages of the game does not alter the inverse relation between the rate of technological spillovers $(\beta)$ and the levels of $\mathrm{R} \& \mathrm{D}$ activities observed in the two previous models. As with $\mathrm{R} \& \mathrm{D}$ coordination only, observed production levels are positively correlated with the scope of externalities. Also, all social welfare components, i.e., consumer surplus and firm profits, are increasing functions of $\beta$, similar to when cooperation is limited to the R\&D stage.

TABLE 3. Equilibrium in a fully cartelized industry under linear production costs

\begin{tabular}{|c|c|c|c|c|c|c|}
\hline$\beta$ & $q_{i}$ & $p$ & $x_{i}$ & $C S$ & $\pi_{i}$ & $T W$ \\
\hline 0 & 24,9075 & 50,185 & 1,70368 & 1240,77 & 1237,87 & 3716,5 \\
\hline 0,1 & 24,9124 & 50,1752 & 1,68402 & 1241,26 & 1238,41 & 3718,09 \\
\hline 0,2 & 24,9166 & 50,1668 & 1,66428 & 1241,67 & 1238,9 & 3719,48 \\
\hline 0,3 & 24,9203 & 50,1594 & 1,64477 & 1242,04 & 1239,34 & 3720,72 \\
\hline 0,4 & 24,9237 & 50,1526 & 1,62568 & 1242,38 & 1239,74 & 3721,86 \\
\hline 0,5 & 24,9267 & 50,1466 & 1,60711 & 1242,68 & 1240,1 & 3722,88 \\
\hline 0,6 & 24,9294 & 50,1412 & 1,58913 & 1242,95 & 1240,43 & 3723,81 \\
\hline 0,7 & 24,9319 & 50,1362 & 1,57174 & 1243,20 & 1240,73 & 3724,66 \\
\hline 0,8 & 24,9342 & 50,1316 & 1,55495 & 1243,43 & 1241,01 & 3725,45 \\
\hline 0,9 & 24,9363 & 50,1274 & 1,53877 & 1243,64 & 1241,27 & 3726,18 \\
\hline 1 & 24,9382 & 50,1236 & 1,52316 & 1243,83 & 1241,51 & 3726,85 \\
\hline
\end{tabular}

Source: own calculations. 
By comparing Tables 2 and 3, we may conclude that the cartel arrangement at both stages of the game leads to greater research investments, in comparison to the case of cooperation limited to the R\&D stage, for any level of technological spillovers. However, a comparison of Tables 1 and 3 shows that switching from full competition to full cooperation reduces the size of $R \& D$ activities for lower values of $\beta(\beta<0,5)$, and results in larger research investments when externalities play a more significant role in technology development $(\beta \geq 0,5)$.

Full cartelization of the industry is equivalent to a monopolist controlling the entire value chain. Therefore, the equilibrium level of output in this case is the lowest among all models for any scope of technological spillovers. It is, clearly, detrimental to the interests of the final-product buyers who obtain the smallest consumer surplus.

Fully-cooperating firms are the key beneficiaries of industry cartelization. Firm profits obtained in this model are the highest of the above cases. However, despite a significant profit increase from full industry cartelization, the absolute reduction in the consumer surplus is substantially greater, i.e. a dead-weight loss occurs. Therefore, under the assumption of linear costs of production, social welfare measured by the sum of consumer surplus and firm profits achieves the lowest value when companies are allowed to fully cartelize the industry.

\section{Gains from R\&D Activities under Quadratic Cost Functions}

After examining the impact of $R \& D$ investments on social welfare under the linear cost setting, we next analyze gains from research activities when firms are subject to diseconomies of scale in manufacturing the final product. Our aim here is to compare the equilibrium results obtained in both models. The welfare analysis in this section is based on the model introduced by Prokop [2014].

As with linear production costs, we consider a similar two-stage game played by two firms. Players may decide either to engage in a Cournot-type competition at both stages, or to create an $\mathrm{R} \& \mathrm{D}$ cartel and then either compete in the final-product market or fully cartelize the industry. Similar to the previous model, cost-reducing investments of each firm generate positive externalities for the rival. The key difference between the previously analyzed model lies in the character of the cost function. Now, we assume that both companies manufacture the final product at costs described by the following quadratic function

$$
C_{i}\left(q_{i}, x_{i}, x_{j}\right)=\frac{q_{i}^{2}}{c+x_{i}+\beta x_{j}} .
$$

Each firm incurs R\&D investment costs according to the function given by formula (3) in the previous section. 
Like the model with linear production costs, market demand is linear and the inverse demand function has the form given by formula (1). Therefore, the profit of each firm $i$ is given by

$$
\pi_{i}\left(q_{i}, q_{j}, x_{i}, x_{j}\right)=(a-b Q) q_{i}-\frac{q_{i}^{2}}{c+x_{i}+\beta x_{j}}-\gamma \frac{x_{i}^{2}}{2} .
$$

The game is played sequentially with no private information and simultaneous moves at every stage. Again, our solution concept is the symmetric Nash equilibrium in pure strategies, which takes the form of a pair of strategic variables $\left(x_{i}, q_{i}\right)$ for $i=1,2$.

We use our model to conduct numerical simulations of the equilibrium decisions of the firms and resulting welfare effects. The main focus has been set on the impact of cooperative behavior on the consumer surplus and total welfare for different levels of technological spillovers.

Although, a direct quantitative comparison of both models cannot be performed due to different cost settings, we parameterize the latter model identically to the first one. Thus, the parameters are assumed to be as follows: $a=100, b=1, c=1, \gamma=2$. As before, parameter $\beta$ will vary between 0 and 1 .

As with the previous model, three market situations in terms of cooperation will be discussed: full competition, cooperation limited to $\mathrm{R} \& \mathrm{D}$, and full cooperation.

Table 4 provides the results of numerical simulations for fully competing firms, i.e. simultaneous and independent cost-reducing investments at the first stage of the game and Cournot-type competition in the final-product market. The table gives the equilibrium values of strategic variables and resulting gains from investments for various spillover levels.

It follows from Table 4 that, as in the case of quadratic cost functions, there is a negative correlation between R\&D expenses and technological spillovers, which results from the inverse relationship between marginal costs and the extent of externalities measured by parameter $\beta$.

The level of final-product supply behaves non-monotonically in response to changes of research externalities. For the values of parameter $\beta$ not greater than 0,2 , an increase in the size of research spillovers results in a bigger supply of the final product. When the externalities measured by $\beta$ exceeded 0,2 , their increase led to a decline of final output. This is a qualitatively similar result to the case of full competition under the linear production costs reported in Table 1. There was a maximum of production size inside the acceptable range of the spillover effect (specifically, at $\beta=0,5$ ).

Consumer surplus is closely linked to firm production levels, and is therefore maximized at the same value of the spillover parameter. Hence, for $\beta=0,2$ consumer benefits are maximized. However, firm profits are not the highest at this level of spillovers. According to Table 4 , profits are an increasing function of the extent of externalities, $\beta$, over the range between 0 and 0,9 , and are only slightly declining for $\beta \in[0,9 ; 1]$. Thus, in this case, firms benefit from a much higher level of technological spillovers than do consumers. 
TABLE 4. Cournot equilibrium for quadratic cost functions and various levels of spillovers

\begin{tabular}{|c|c|c|c|c|c|c|}
\hline$\beta$ & $q_{i}$ & $p$ & $x_{i}$ & $C S$ & $\pi_{i}$ & $T W$ \\
\hline 0,0 & 31,1170 & 37,7660 & 8,35987 & 1936,53 & 1001,83 & 3940,19 \\
\hline 0,1 & 31,1293 & 37,7415 & 7,65065 & 1938,06 & 1013,42 & 3964,89 \\
\hline 0,2 & 31,1309 & 37,7381 & 7,01948 & 1938,27 & 1022,71 & 3983,68 \\
\hline 0,3 & 31,1222 & 37,7556 & 6,44876 & 1937,18 & 1030,23 & 3997,63 \\
\hline 0,4 & 31,1025 & 37,7949 & 5,92496 & 1934,74 & 1036,34 & 4007,41 \\
\hline 0,5 & 31,0710 & 37,8580 & 5,43729 & 1930,81 & 1041,28 & 4013,38 \\
\hline 0,6 & 31,0256 & 37,9489 & 4,97665 & 1925,13 & 1045,22 & 4015,61 \\
\hline 0,7 & 30,9632 & 38,0735 & 4,53493 & 1917,44 & 1048,24 & 4013,91 \\
\hline 0,8 & 30,8790 & 38,2419 & 4,10432 & 1907,03 & 1050,35 & 4007,73 \\
\hline 0,9 & 30,7650 & 38,4701 & 3,67665 & 1892,97 & 1051,49 & 3995,95 \\
\hline 1,0 & 30,6073 & 38,7854 & 3,24257 & 1873,61 & 1051,45 & 3976,51 \\
\hline
\end{tabular}

Source: own calculations.

The total measure of social welfare, obtained as the sum of consumer surplus and firm profits, is reported in the last column of Table 4. The maximum total welfare level is reached at $\beta=0,6$. Thus, a medium range of technological spillovers is most preferred from the social welfare viewpoint when companies engage in competition at both stages of the game and produce at costs characterized by quadratic functions. This conclusion is qualitatively different from the case of full competition under the linear production costs illustrated by Table 1 . In that case, total welfare was maximized for the levels of spillovers close to 1,0 .

Table 5 presents the numerical results for the model in which firms cooperate in R\&D investments and compete a la Cournot in the final-product market under the assumption of quadratic cost functions. Similar to our previously considered models, we observe here a natural decrease in R\&D activity when the size of technological spillovers is growing. Analogously to the case of research cooperation under linear cost functions, this decrease in $R \& D$ investments does not negatively impact the production levels of firms, i.e. a higher extent of technological externalities generates a larger final output in equilibrium.

The positive relationship between technological spillover size and equilibrium output results in the lowest price of the final product when there is perfect knowledge transfer between companies $(\beta=1)$. Since consumer surplus is strictly linked to production levels, it achieves the highest value at the greatest extent of technological externalities, as well.

Enterprises profits are also an increasing function of technological spillovers. Therefore, total welfare, as the sum of consumer surplus and firm profits, grows together with higher values of parameter $\beta$, and is maximized at the greatest extent of research externalities $(\beta=1)$. 
TABLE 5. Equilibrium in the model of R\&D cartel under quadratic cost functions

\begin{tabular}{|c|c|c|c|c|c|c|}
\hline$\beta$ & $q_{i}$ & $p$ & $x_{i}$ & $C S$ & $\pi_{i}$ & $T W$ \\
\hline 0,0 & 30,0000 & 40,0000 & 5,00000 & 1800,000 & 1025,00 & 3850,000 \\
\hline 0,1 & 30,1775 & 39,6450 & 4,88624 & 1821,363 & 1029,66 & 3880,683 \\
\hline 0,2 & 30,3324 & 39,3352 & 4,78209 & 1840,109 & 1033,72 & 3907,549 \\
\hline 0,3 & 30,4692 & 39,0616 & 4,68628 & 1856,744 & 1037,31 & 3931,364 \\
\hline 0,4 & 30,5910 & 38,8180 & 4,59773 & 1871,619 & 1040,51 & 3952,639 \\
\hline 0,5 & 30,7004 & 38,5992 & 4,51556 & 1885,029 & 1043,37 & 3971,769 \\
\hline 0,6 & 30,7992 & 38,4016 & 4,43902 & 1897,181 & 1045,96 & 3989,101 \\
\hline 0,7 & 30,8890 & 38,2220 & 4,36748 & 1908,261 & 1048,31 & 4004,881 \\
\hline 0,8 & 30,9711 & 38,0578 & 4,30039 & 1918,418 & 1050,46 & 4019,338 \\
\hline 0,9 & 31,0465 & 37,9070 & 4,23729 & 1927,770 & 1052,43 & 4032,630 \\
\hline 1,0 & 31,1160 & 37,7680 & 4,17780 & 1936,411 & 1054,24 & 4044,891 \\
\hline
\end{tabular}

S o u r c e: own calculations.

It seems quite natural that the cooperation of firms at the R\&D stage enables them to obtain higher profits than in the fully competitive situation. Less intuitive, however, is that for the large values of spillovers $(\beta \geq 0,8)$, consumers gain from firm research cooperation, as well. When research externalities are not too high $(\beta<0,8)$, consumer surplus is lower when there is research coordination than under full competition.

A comparison of the last columns of Tables 2 and 5 shows that the behavior of total welfare in response to the size of technological spillovers in the case of R\&D cooperation is qualitatively independent of the type of cost functions.

Finally, we consider the case of full industry cartelization when production costs are characterized by a quadratic function. In this model, the industry is practically controlled by a monopolistic firm composed of two R\&D facilities and two production plants, both exhibiting diseconomies of scale and research activities linked by parameter $\beta$. Table 6 presents the equilibrium results of the numerical simulations in this setting.

As in the other analyzed models, in this setting there is a negative relationship between technological spillovers and R\&D investments in equilibrium. Despite falling research activity, final-output level increase from greater technological externalities. This effect is caused by declining marginal costs generated by higher spillovers. The largest equilibrium supply is observed when there is perfect transfer of technological improvements between both research facilities.

Both components of total welfare, i.e., consumer surplus and firm profits, are increasing functions of the spillover parameter $\beta$. Thus, total welfare grows together with the extent of externalities. Hence, the maximum values of consumer surplus, firm profits, and total welfare are reached at the largest level of technological spillovers. This result is not different from the equilibrium found in the model with no diseconomies of scale in production. 
TABLE 6. Equilibrium in the fully cartelized industry under quadratic production costs

\begin{tabular}{|c|c|c|c|c|c|c|}
\hline$\beta$ & $q_{i}$ & $p$ & $x_{i}$ & $C S$ & $\pi_{i}$ & $T W$ \\
\hline 0,0 & 23,2934 & 53,4131 & 5,82468 & 1085,17 & 1130,75 & 3346,66 \\
\hline 0,1 & 23,3907 & 53,2186 & 5,69762 & 1094,25 & 1137,07 & 3368,40 \\
\hline 0,2 & 23,4751 & 53,0498 & 5,58094 & 1102,16 & 1142,51 & 3387,37 \\
\hline 0,3 & 23,5491 & 52,9018 & 5,47332 & 1109,12 & 1147,50 & 3404,11 \\
\hline 0,4 & 23,6147 & 52,7707 & 5,37363 & 1115,30 & 1151,86 & 3419,02 \\
\hline 0,5 & 23,6732 & 52,6535 & 5,28093 & 1120,84 & 1155,77 & 3432,39 \\
\hline 0,6 & 23,7259 & 52,5481 & 5,19442 & 1125,84 & 1159,31 & 3444,47 \\
\hline 0,7 & 23,7736 & 52,4527 & 5,11342 & 1130,37 & 1162,54 & 3455,44 \\
\hline 0,8 & 23,8171 & 52,3658 & 5,03734 & 1134,51 & 1165,48 & 3465,47 \\
\hline 0,9 & 23,8569 & 52,2863 & 4,96570 & 1138,30 & 1168,19 & 3474,67 \\
\hline 1,0 & 23,8934 & 52,2132 & 4,89805 & 1141,79 & 1170,68 & 3483,15 \\
\hline
\end{tabular}

Source: own calculations.

Full cartelization of the industry naturally enhances firm profits, but leads to a significantly higher price in comparison to less cartelized markets. Thus, consumers are harmed, as reflected in low consumer surplus values. Such strong price increases generate societal losses, which cannot be compensated by additional firm profits, and therefore lead to the dead-weight loss. The cooperation of firms at both stages of the game causes total welfare equilibrium to be the lowest among all three models with quadratic production costs for any scope of technological spillovers. Unfortunately, firms will have strong incentives to cooperate at both stages, since their profits are the highest in this case. ${ }^{5}$

\section{Conclusion}

In this paper, we analyzed the impact of R\&D investments on consumer surplus and social welfare under three different forms of oligopolistic competition and two types of cost functions.

Our numerical analysis showed that the functional form of production costs has a qualitative impact on welfare when firms simultaneously and independently choose the size of $R \& D$ investments at the initial stage, and the quantities of supply at the second stage (full competition). In the case of full competition under linear production costs (Table 1 ), total welfare was maximized for the highest levels of spillovers ( $\beta$ close to 1,0$)$. When the production costs were characterized by quadratic functions (Table 4 ), the medium range of technological spillovers $(\beta=0,5)$ was most preferred from the social welfare viewpoint.

However, when firms cooperate at the R\&D stage or fully cartelize the industry, welfare effects are invariant to the shape of the cost functions. Moreover, for high levels 
of technological spillovers $(\beta \geq 0,8)$, total welfare is highest when firms engage in cooperation at the R\&D stage, and compete in the final product market, regardless of whether production costs are characterized by linear or quadratic functions. When the extent of externalities is relatively small $(\beta<0,5)$, social welfare is maximized by fully competing firms independent of cost function type. Hence, as a matter of public policy, cooperation by firms should be limited, or banned, when the extent of R\&D spillovers is low.

We should, also, stress that total welfare in the case of cooperation limited to R\&D stage always dominates the social benefits from full cartelization of industry for both types of cost functions and for all levels of technological spillovers. Thus, our analysis confirms the key policy recommendation that $\mathrm{R} \& \mathrm{D}$ cooperation should be supported when the degree of technological externalities is high, but collusion in the final product market should never be allowed.

The results obtained in this paper regarding the welfare effects of R\&D activities in oligopoly are largely based on a limited numerical analysis. Clearly, it is important to investigate the robustness of our findings to the fluctuations of the key parameters of the model.

A suggested directions of additional research would be to consider more general types of cost functions and other forms of competition among firms.

\section{Notes}

Jacek Prokop - corresponding author: jacek.prokop@sgh.waw.pl

Bartłomiej Wiśnicki, M.A. student, Warsaw School of Economics: bart.wisnicki@gmail.com

Compare, for example, Bloom et al. [2013].

See, for example, Spence [1984].

5 The analysis of incentives to cartelize the industries by oligopolists engaged in R\&D activities can be found in, for example, Prokop and Karbowski [2013].

\section{References}

d'Aspremont, C., Jacquemin, A. (1988), Cooperative and noncooperative R\&D in duopoly, The American Economic Review, 78, pp. 1133-1137.

Bloom, N., Schankerman, M.,Van Reenen, J. (2013), Identifying technology spillovers and product market rivalry, Econometrica, 81, No. 4, pp. 1347-1393.

De Fraja, G., Silipo, D.B. (2002), Product market competition, R\&D and welfare, Research in Economics, 56, No. 4, pp. 381-397. 
Kamien, M.I., Muller, E., Zang I. (1992), Research Joint Ventures and R\&D Cartels, The American Economic Review, 82, pp. 1293-1306.

Prokop, J. (2014), Wspólne przedsięwzięcia badawczo-rozwojowe w duopolu z kwadratowymi kosztami produkcji (Research Joint Ventures in a Duopoly with Quadratic Cost Functions), Zeszyty Naukowe Uniwersytetu Szczecińskiego, 810, Studia i Prace Wydziału Nauk Ekonomicznych i Zarządzania, No. 35(2), pp. $195-207$.

Prokop, J., Karbowski A. (2013), R\&D cooperation and industry cartelization, Economics Discussion Papers, Kiel Institute for the World Economy.

Spence, M. (1984), Cost reduction, competition, and industry performance, Econometrica, 52, No. 1, pp. $101-121$. 